\title{
Juvenile hepatic fibropolycystic disease and other abnormalities
}

\author{
J. E. CARTY \\ Ch.B., M.R.C.P.(U.K.)
}

\author{
C. T. A. Jones
}

M.B. Ch.B., M.R.C.P.

University Department of Medicine, The Royal Infirmary, Manchester

\begin{abstract}
Summary
Two cases are described of hepatic fibropolycystic disease (Brunt, 1973). Both had neonatal pyloric stenosis, one craniostenosis and the other acromegaly and neuro-fibromatosis.
\end{abstract}

\section{Case reports}

Case 1

This man first presented at the age of three months with pyloric stenosis, for which Rammstedt's operation was performed. When he was 9 years old his 7-year-old sister was found to have hepatosplenomegaly. He was also found to have hepatosplenomegaly. His blood urea then was $5.3 \mathrm{mmol} / \mathrm{l}$.

He was seen in The Royal Infirmary, Manchester, at the age of 41 years when he complained of lethargy. Investigation showed him to have acromegaly due to a pituitary tumour, neurofibromatosis, hepato-splenomegaly, oesophageal varices and enlarged cystic kidneys. As a result of the latter he had chronic renal failure. The pituitary tumour was treated with radiotherapy to the pituitary fossa after which renal failure progressed despite dialysis.

Post-mortem revealed the liver ( $3775 \mathrm{~g}$ ) and spleen $(625 \mathrm{~g})$ to be enlarged. The kidneys were of differing sizes (left $275 \mathrm{~g}$, right $140 \mathrm{~g}$ ) (Fig. 1). To the naked eye, both appeared polycystic. A necrotic pituitary tumour was found.

The liver had a smooth capsule and was firm to the knife. The cut surface had a mosaic appearance with brown areas of liver tissue being broken up by white bands of fibrous tissue. There were no obvious cysts. On microscopy, the findings were typical of congenital hepatic fibrosis with strands of fibrous tissue within the portal tracts. The bile ducts appeared to be proliferating and there was some evidence of biliary stasis (Fig. 2).

The capsules of the kidneys were adherent. The cortices measured up to $5 \mathrm{~mm}$ in thickness and were sponge-like. The cysts in the kidneys were up to $2 \mathrm{~cm}$ in diameter and some contained green pus and necrotic debris. On histology in the cortices there was fibrosis around the glomeruli which were sparse

Correspondence: J. E. Carty, Department of Rheumatology, Manchester Royal Infirmary, Oxford Road, Manchester M13 9WL.

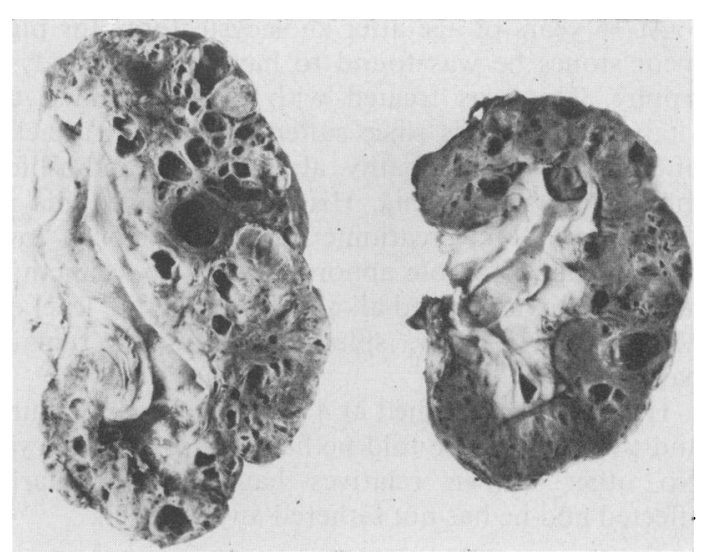

FIG. 1. Case 1. Cut surface of both kidneys. The larger is the left kidney.

(Fig. 3). There were many cysts lined with flattened epithelium, and some of these contained casts. In the smaller right kidney there were areas of scarring, consistent with chronic pyelonephritis.

The sister was not investigated by the authors but when aged 21 years she was said still to be suffering from hepatosplenomegaly. A barium meal had not shown oesophageal varices. Her kidneys were not palpable and her blood urea was $6.4 \mathrm{mmol} / \mathrm{l}$. Intravenous pyelography had not been performed.

Both the patient's parents were healthy into old age, and his children have been thoroughly investigated and appear free of renal or hepatic disease.

\section{Case 2}

This 27-year-old man was found to have enlarged kidneys when he was 3 months old. Shortly afterwards he developed pyloric stenosis and Rammstedt's operation was performed. There followed surgery for craniostenosis at 18 months, at which time both his liver and spleen were palpable. Routine biochemistry revealed a blood urea of $11 \cdot 2$ $\mathrm{mmol} / \mathrm{l}$.

He remained moderately well until the age of 14 years when he had a haematemesis from oesophageal varices. During surgery to construct a portocaval 
anastomosis the liver was found to be fibrotic and the spleen enlarged. The kidneys seemed polycystic and quite large cysts could be palpated on the surfaces. Biopsies were taken of the liver but not of the kidneys. The liver sections showed proliferation and dilatation of the portal tract bile ducts which contained inspissated bile fragments. There was some mild inflammatory change around the fibrotic areas. The liver lobules appeared fairly normal but they contained a few focal areas of necrosis without obvious regeneration.

At 16 years of age after cholecystectomy for pigment stones he was found to have renal osteodystrophy. This was treated with and responded to vitamin D. He has since suffered recurrent attacks of hepatic encephalopathy, about $2 /$ year, and a lifethreatening septicaemia. His present blood urea is $18.4 \mathrm{mmol} / 1$ and creatinine $0.57 \mathrm{mmol} / 1$ on a low protein diet. The sole abnormality of liver function tests is a slightly raised alkaline phosphatase level of 115 i.u./l. His liver, spleen and kidneys remain palpable.

His only brother died at 4 months in renal failure and the family were told he had polycystic kidneys. No other known relatives have been similarly affected and he has not fathered any children.

\section{Discussion}

The age of presentation, histology and the relative preponderance of the renal or hepatic lesion are the bases of the classification of hepatic fibropolycystic disease into four subgroups, perinatal, neonatal, infantile and juvenile (Blyth and Ockenden, 1971). All four types have recessive inheritance; each type breeding true within a family.

It is difficult to fit case 1 into this classification since although hepatosplenomegaly was noted at 9 years, there were no clinical manifestations of hepatic or renal disease until middle life.

It is said that affected siblings manifest the same subgroup of hepatic fibropolycystic disease and that they present at approximately the same age as did this patient and his sister (Blyth and Ockenden, 1971). This is cited as evidence for a subgrouping of hepatic fibropolycystic disease on genetic grounds. A further theory suggests the involvement of mutant alleles with intermediate forms of the disease being due to compound heterozygotes (Murray-Lyon, Ockenden and Williams, 1973).

The kidneys of case 1 were more reminiscent of adult disease, i.e. generalized involvement and large cysts rather than simple tubular dilatation, but the changes had had at least 30 years to evolve, unlike previous series where younger patients are described. Lieberman et al. (1971) in serial studies have shown a transition from juvenile to adult polycystic disease in individual patients.
This man, although clinically having juvenile disease, did not suffer variceal haemorrhage despite his long standing portal hypertension and his renal failure did not become obvious until his early forties. Late onset variceal haemorrhage or renal failure is recognized in juvenile disease (MurrayLyon et al., 1973).

In the second patient, renal disease was found at 3 months and hepatic disease at 18 months; clinically fitting the infantile type of hepatic fibropolycystic disease which usually manifests itself at 3-6 months of age with both chronic renal failure and portal hypertension. His brother, about whom there is little clinical information, died at 4 months in renal failure said to be due to polycystic kidneys. This would be more in accord with the neonatal type of disease but would be in disagreement with the usual situation where each subgroup breeds true within a family.

Although this man has needed surgical portal decompression and has since suffered recurrent attacks of hepatic encephalopathy, his routine biochemical liver function tests only show a moderately elevated alkaline phosphatase level. Kerr et al. (1961) remark on the normality of these tests in this condition even when the liver is grossly enlarged and portal hypertension present.

These patients both had neonatal pyloric stenosis and childhood hepatic fibropolycystic disease, although of differing types. This might be a chance association as neonatal pyloric stenosis is common in males, occurring in $1: 500$ births (Jolly, 1968). The genetics of pyloric stenosis are obscure and Carter (1961) stated that its Mendelian inheritance could not be established. It is, however, slightly more common amongst the subsequent male siblings of a firstborn male who manifests the disease. Previous accounts of hepatic fibropolycystic disease do not mention an association with neonatal pyloric stenosis (Blyth and Ockenden, 1971; Kerr et al., 1961 ; Lieberman et al., 1971). There are no reports of polycystic kidneys and neonatal pyloric stenosis occurring together (McKusick, 1971).

However, if one were to postulate a genetic association between these diseases there are three possible mechanisms. If there are four subgroups of hepatic fibropolycystic disease each with its own gene, then on the basis of these two cases, the gene for pyloric stenosis must be associated with at least two of them. Alternatively, the gene for pyloric stenosis could be associated with the major gene of a compound heterozygote and would therefore allow pyloric stenosis to appear in any of the four subgroups of hepatic fibropolycystic disease. A third, less likely, explanation is that all four subgroups of hepatic fibropolycystic disease are represented by one gene and that it is this one gene that may occur in association with the gene of pyloric stenosis. 


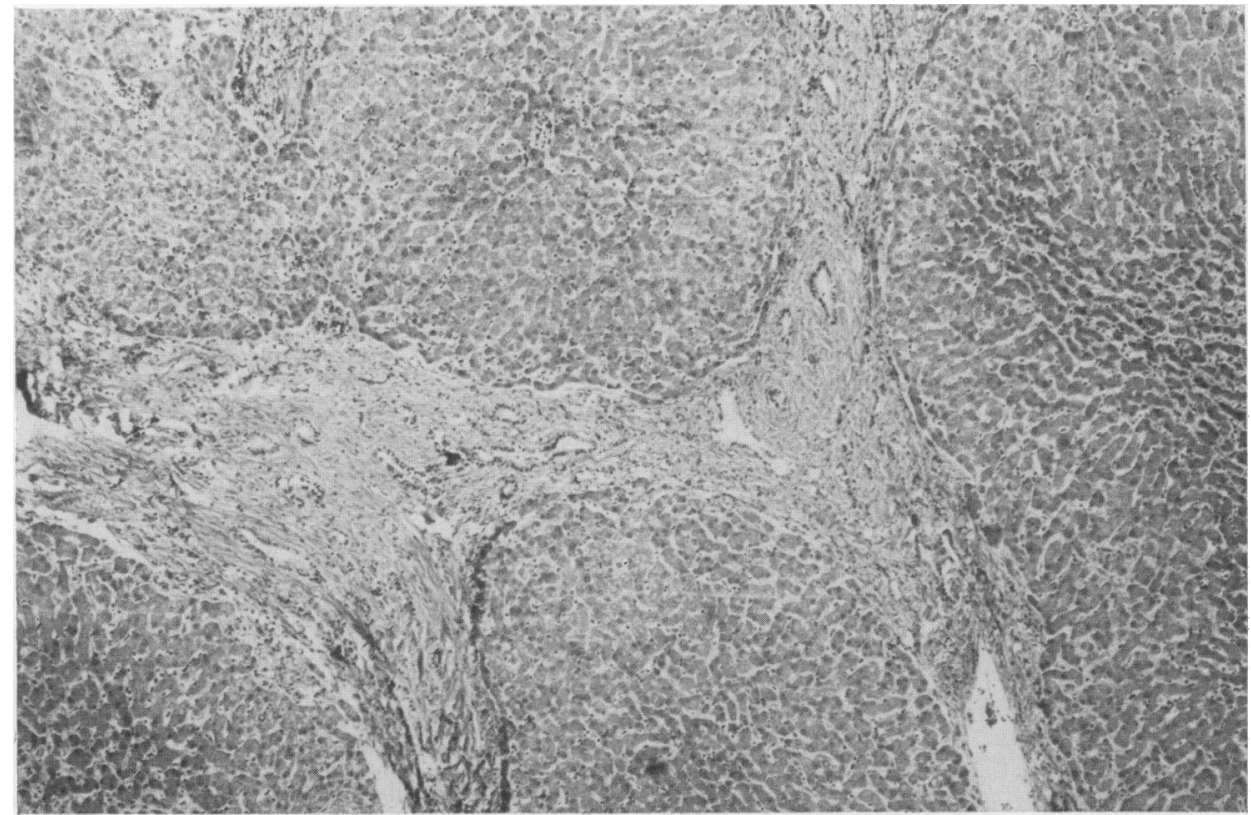

FIG. 2. Case 1. Liver section showing proliferation of bile ducts and portal fibrosis. (Masson's trichrome, $\times 50$. )

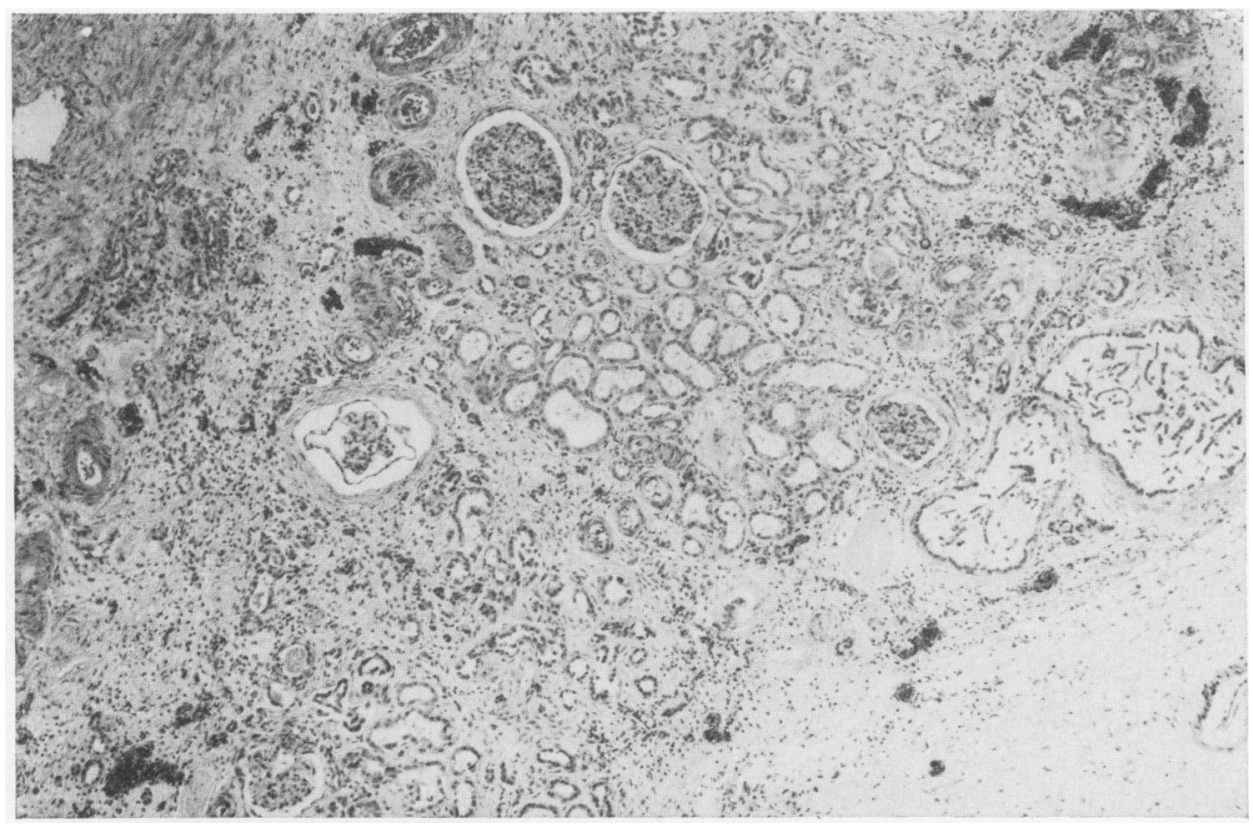

FIG. 3. Case 1. Renal cortex showing periglomerular fibrosis. (HE, $\times 50$.) 
The presence of the other abnormalities is hard to explain genetically. Craniostenosis may be inherited as a recessive (Gaudier et al., 1967). Multiple skull defects have been reported in patients with polycystic renal disease (Staubitz, Jenett and Pletman, 1963) and cerebral malformations occur in the Meckel syndrome which has some similarities to hepatic fibropolycystic disease (Fried et al., 1971; Opitz and Howe, 1969). Acromegaly is usually only inherited as part of the multiple endocrine adenomatous syndrome and then only as a dominant. Von Recklinghausen's neurofibromatosis is relatively common, $1: 3000$ births and genetic factors are not usually recognized (Beeson and McDermott, 1967).

These latter diseases are probably chance associations with perhaps the exception of craniostenosis.

\section{Acknowledgments}

We thank Professor S. W. Stanbury and Dr N. P. Mallick for permission to report these cases and Dr Helen Reid for providing the figures.

\section{References}

Beeson, B.B. \& McDermotr, W. (1967) Textbook of Medicine. 12 th edn, p. 488. W. B. Saunders, London and Philadelphia.
Blyth, H. \& Ockenden, B.G. (1971) Polycystic disease of kidneys and liver presenting in childhood. Journal of Medical Genetics, 8, 257.

BruNT, P.W. (1973) Genetics of liver disease, Clinics in Gastroenterology, 2, 615.

Carter, C.O. (1961) The inheritance of congenital pyloric stenosis. British Medical Bulletin, 17, 251.

Fried, K., Liban, E., Lurie, M., Friedman, S. \& Reisner, S.H. (1971) Polycystic kidneys associated with malformations of the brain, polydactyly and other birth defects in newborn sibs. Journal of Medical Genetics, 8, 285.

Gaudier, B., Laine, E., Fontaine, G., Caster, C. \& FarRIAUX, J.P. (1967) Les craniosynostoses, étude de vingt observations. Archives françaises de pédiatrie, 24, 775.

Jolly, H. (1968) Diseases of Children, 2nd edn, p. 140. Blackwell Scientific Publications, Oxford.

Kerr, D.N.S., Harrison, C.V., Sherlock, S. \& Milnes WALKeR, R. (1961) Congenital hepatic fibrosis. Quarterly Journal of Medicine (N.S.), 30, 91.

Lieberman, E., Salinas-Madrigal, L., Gwinn, J.L., Brennan, P.L., Fine, R.N. \& Landing, B.H. (1971) Infantile polycystic disease of the kidneys and liver. Medicine, 50, 277.

McKusick, V.A. (1971) Mendelian Inheritance in Man. 3rd edn. The Johns Hopkins Press, Baltimore and London.

MurRay-Lyon, I.M., OCKenden, B.G. \& Williams, R.G. (1973) Congenital hepatic fibrosis - is it a single clinical entity? Gastroenterology, 64, 653.

OPITZ, J.M. \& Howe, J.J. (1969) The Meckel Syndrome, birth defects. Original Article Series, 2, p. 167. The National Foundation. March of Dimes, New York.

Staubitz, J., Jenett, T.C. \& Pletman, R.J. (1963) Renal cystic disease in childhood. Journal of Urology, 90, 8. 